\title{
Fermilab
}

Fermilab-TM-2699-AD

\section{Energy Deposition, Radiological and Thermal Studies for Linac-to-Booster Transfer Line Beam Absorber}

\author{
Igor Rakhno, Yun He, Ioanis Kourbanis, Vladimir Sidorov, Meiqin Xiao
}

January 25, 2019

\section{Introduction}

The PIP-II Linac-to-Booster transfer line will transport the beam from the end of the superconducting Linac to the Injection Girder of the Booster [1]. The transfer line consists of two arcs and a straight section in between (see Fig. 1). The straight section splits into two separate lines: Beam Absorber and Mu2e experiment lines. In this paper, results of energy deposition studies for the Beam Absorber, performed with MARS15 Monte Carlo code [2-3] for normal operation, are presented. Also, corresponding thermal analyses with ANSYS code [4] are described. According to PIP-II design parameters, the beam energy as high as $1 \mathrm{GeV}$ is considered. Two beam power options were studied: (i) $50 \mathrm{~kW}$ as a conservative estimate for a permanent absorber; (ii) $5 \mathrm{~kW}$ as an option for a portable absorber required for a commissioning stage.

\section{MARS15 model of the Beam Absorber}

Acceptable design parameters for the Beam Absorber have been achieved after several iterations during the numerical studies. The final model of the Absorber is shown in Figs. 2 thru 4. The absorber core consists of two parts. The first part is a graphite cylinder $8 \mathrm{~cm}$ in radius and $100 \mathrm{~cm}$ in length surrounded by an aluminum and steel layers in transverse direction (Fig. 2). The channels with cooling water are gun-drilled inside the aluminum. The second part comes immediately downstream of the first one and it keeps the same transverse structure, including the cooling channels, except for the following: the graphite is replaced with aluminum (see Fig. 3). The length of the second part is $90 \mathrm{~cm}$. The major goal of design iterations regarding the absorber core structure was preventing the core from being melted down or oxidized and maintaining absorber core operational temperature below certain level $\left(400^{\circ} \mathrm{C}\right)$ with a reasonable cooling water flow rate.

The absorber core is surrounded with concrete in order to reduce both residual dose on the absorber external surfaces and ground water (and surface water) activation. A design goal was to keep the

This manuscript has been authored by Fermi Research Alliance, LLC under Contract No. DE- 1 AC02-07CH11359 with the U.S. Department of Energy, Office of Science, Office of High Energy Physics. 
concrete at an operating temperature not exceeding approximately $100^{\circ} \mathrm{C}$. The complete model with concrete shielding (which is not water-cooled) is shown in Fig. 4.

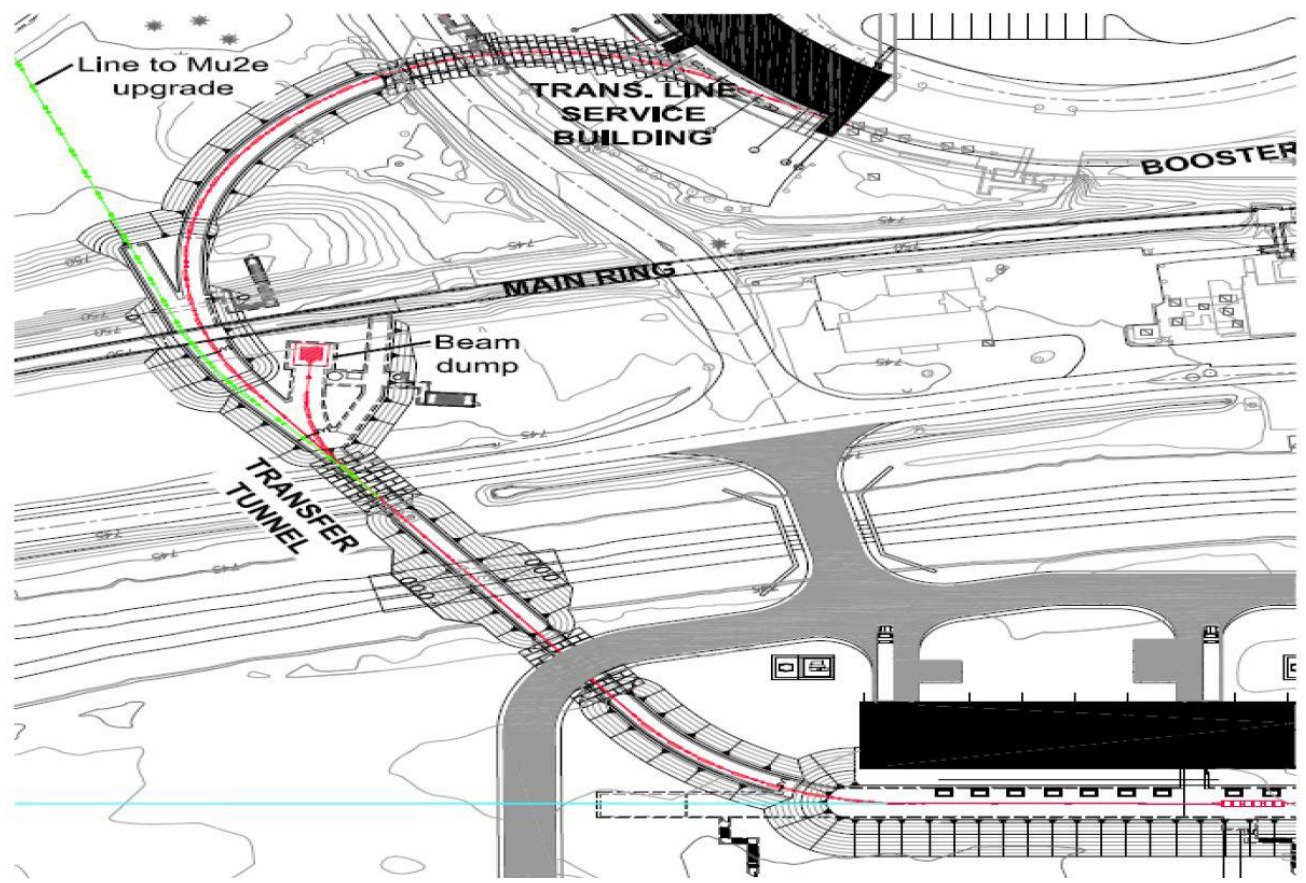

Fig. 1. Layout of PIP-II transfer line.

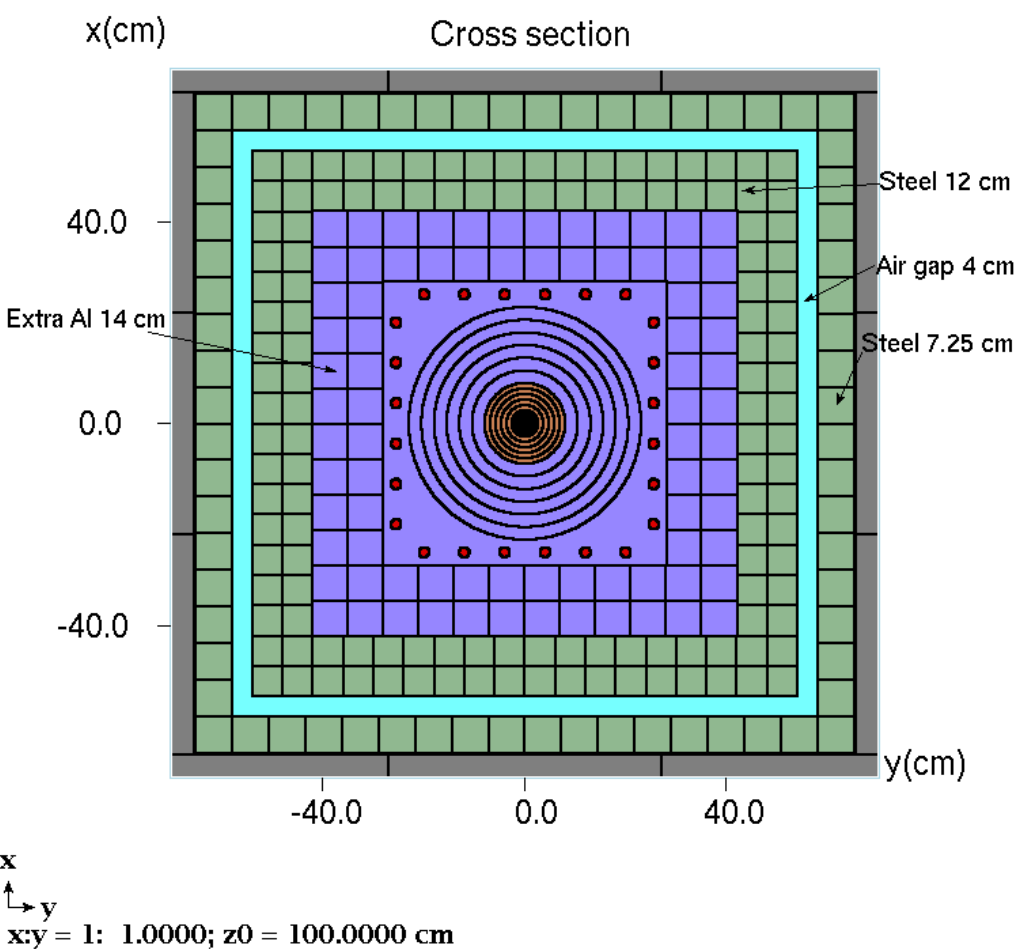

Fig. 2. A cross section of the absorber core with graphite, aluminum and steel regions. The air gaps between the steel layers are to improve heat transfer. The channels with cooling water are shown with red color. 


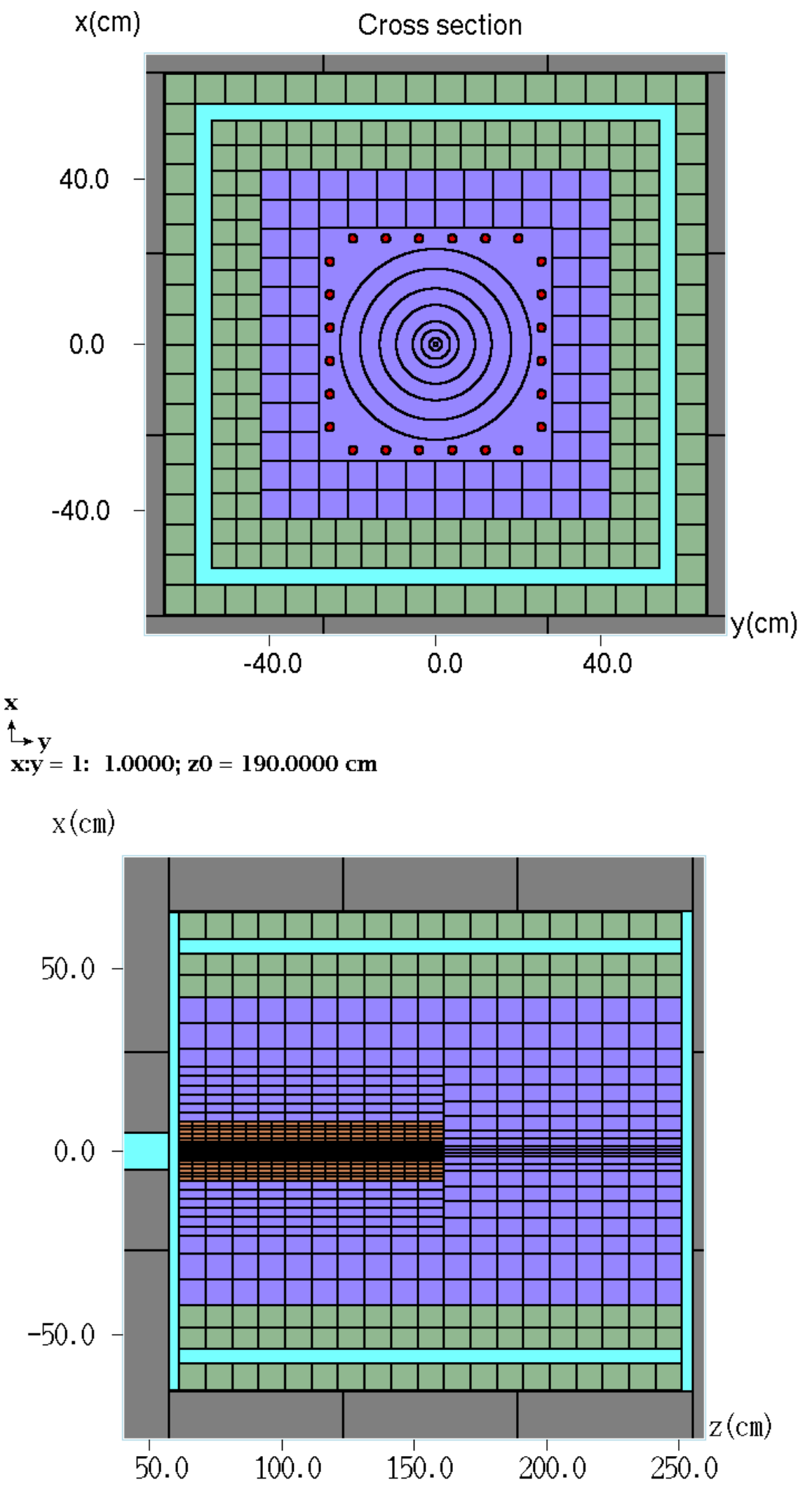

Fig. 3. A cross section of the second part of the absorber core (top) and elevation view of the full absorber core (bottom). The channels with cooling water are shown with red color. 

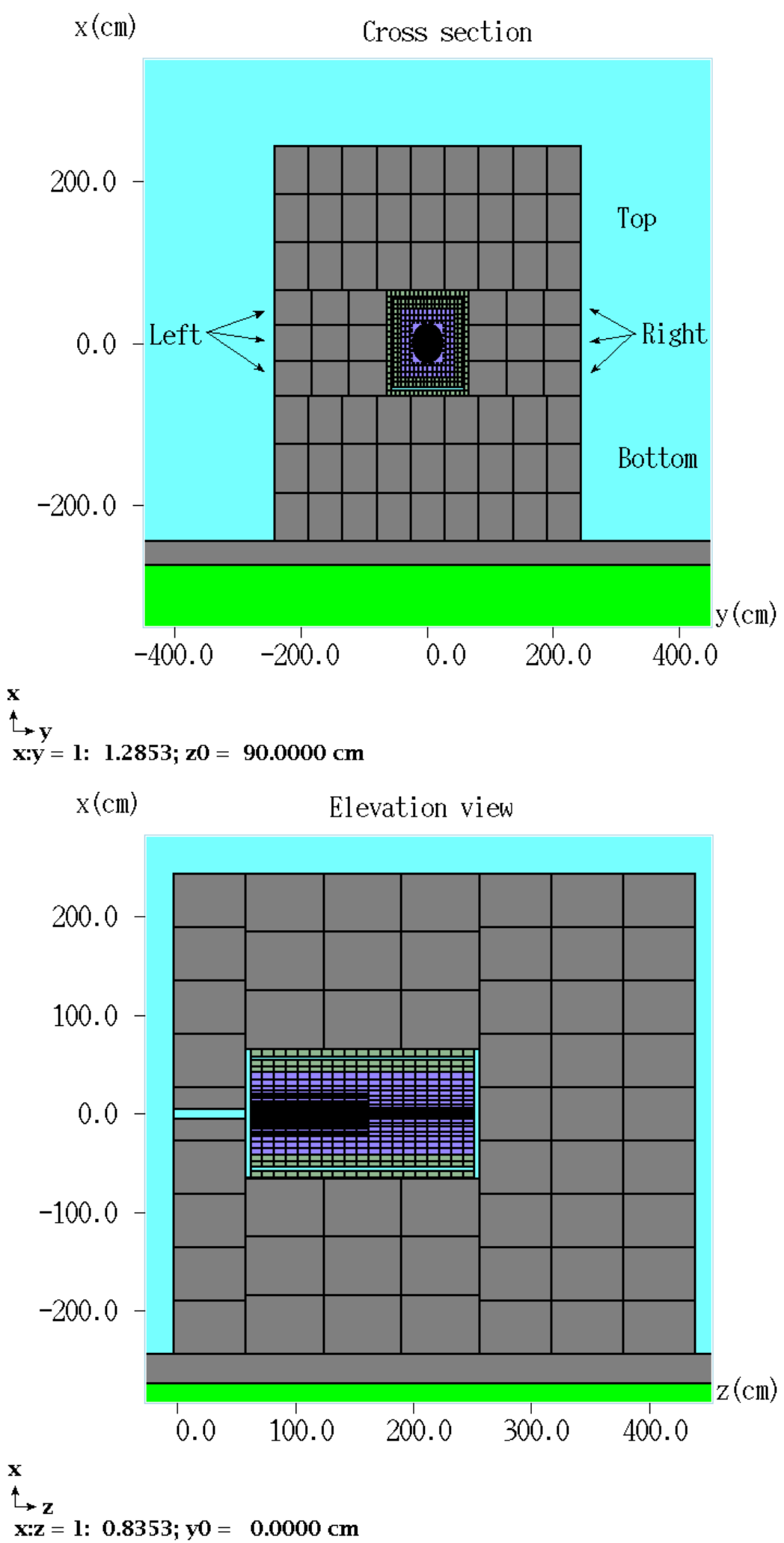

Fig. 4. A cross section (top) and elevation view (bottom) of the full absorber model. Concrete and soil are shown with grey and green colors, respectively. 


\section{Beam parameters and description of the beam sweeping scheme}

The beam consists of negatively charged hydrogen ions, $\mathrm{H}^{-}$, with kinetic energy of $1 \mathrm{GeV}$. Repetition rate is $20 \mathrm{~Hz}$ and linac pulse duration is $0.55 \mathrm{msec}$. For these studies, both horizontal and vertical beam size $(\sigma)$ were assumed to be $2.5 \mathrm{~mm}$. First, energy deposition calculations with permanent beam were performed, when the beam is always directed towards the same point. A subsequent thermal analysis revealed that in such a case it is not possible to reach design goals with a reasonable safety factor. Therefore, a beam sweeping scheme was developed that allows us to spread the deposited beam energy over a larger area which facilitates heat transfer. The sweeping scheme is described in Fig. 5.

- Start at $-11.309 \mathrm{~mm}$ radius and -90 degrees.

- Move by +18 degrees every $50 \mathrm{msec}$.

- End up at the same point in 20 pulses or $1 \mathrm{sec}$

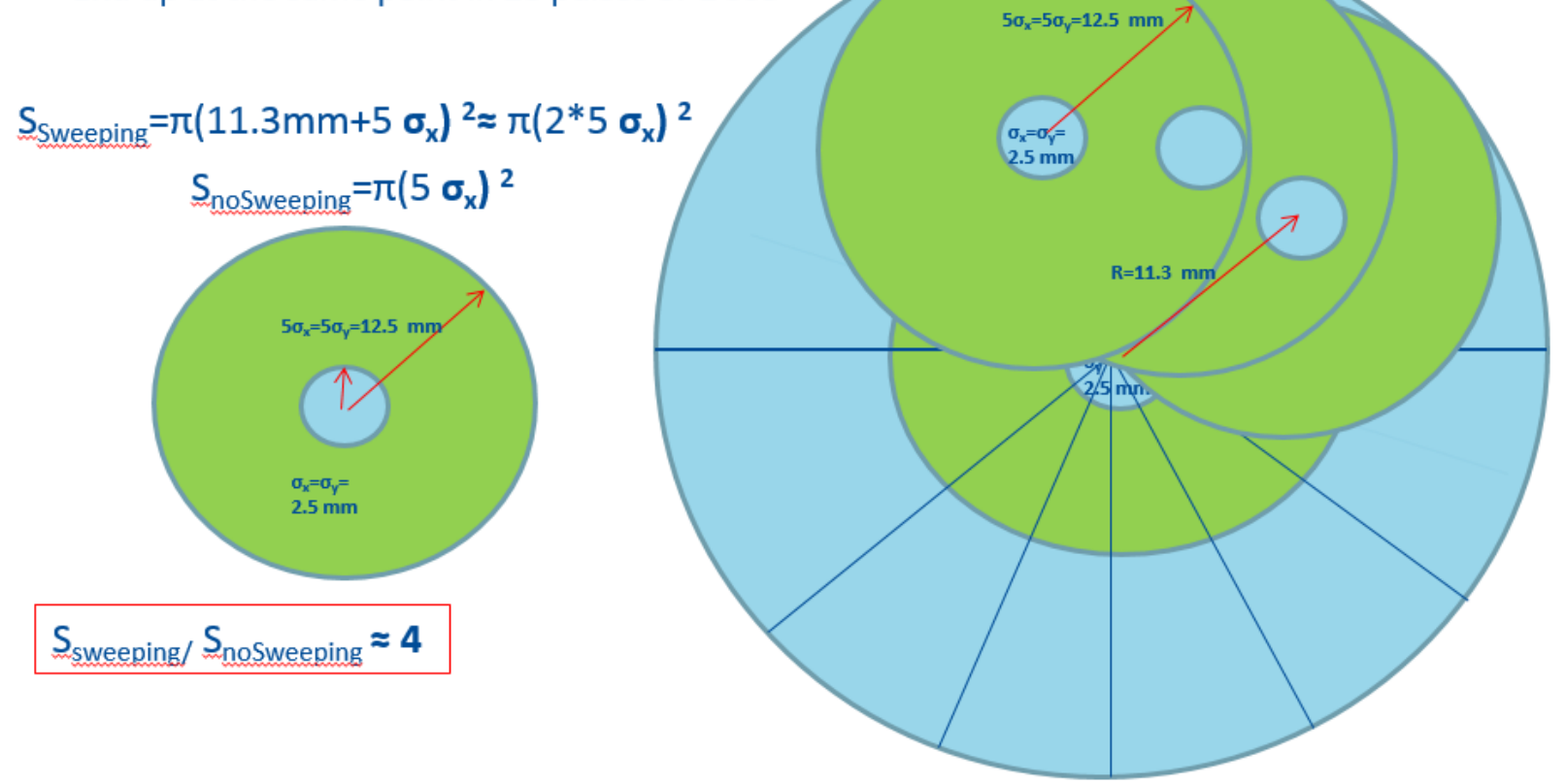

The area of beam energy dissipation is increased by 4 times

Fig. 5. A description of the beam sweeping scheme employed to reduce peak energy deposition in the absorber.

\section{Calculated energy deposition, dose and other distributions}

\subsection{A $50-\mathrm{kW}$ case}

The calculated distribution of power density in the Beam Absorber is shown in Fig. 6. A detailed three-dimensional power density distribution, corresponding to this case, was used for subsequent thermal analysis with ANSYS code. 
From operational standpoint, distributions of residual dose over the surface of the Beam Absorber are essential for personal radiation safety. One can see in Fig. 7 that front face of the Beam Absorber can get significantly activated, approximately 100 time more than the prescribed level of $1 \mathrm{mSv} / \mathrm{hr}(100 \mathrm{mrem} / \mathrm{hr})$ [5]. This issue can be mitigated by means of using a marble layer on the front surface of the absorber. The material can provide a significant reduction of the contact residual dose. In Fig. 8 one can see that a marble layer as thick as 8 " provides a dose reduction factor of about 35 .

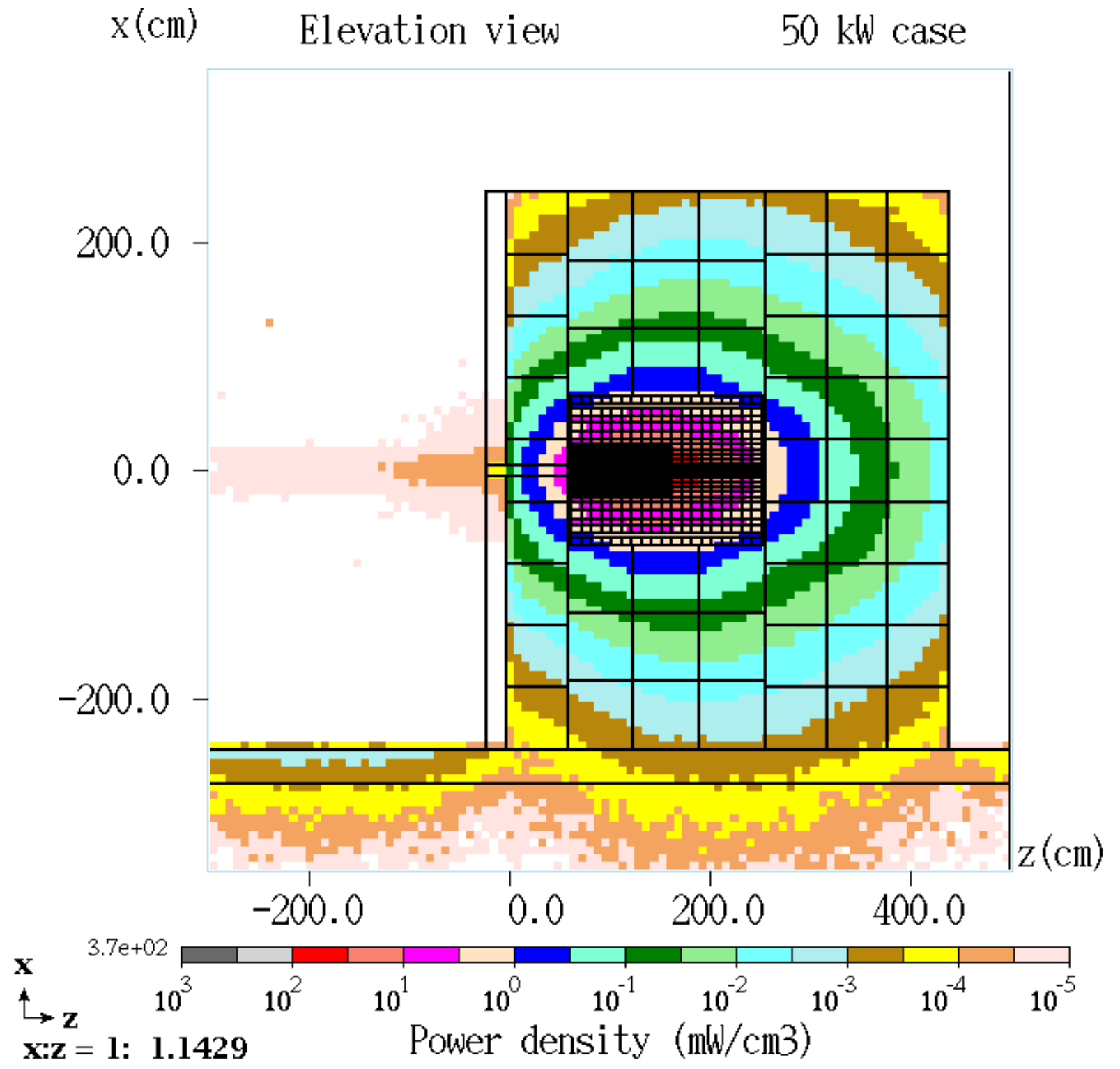

Fig. 6. A calculated power density distribution in the absorber core and surrounding concrete shielding. The black region in the first part of the absorber core corresponds to large number of small bins, so that the black lines which separate the neighbor bins practically coincide, given the limited picture resolution. 


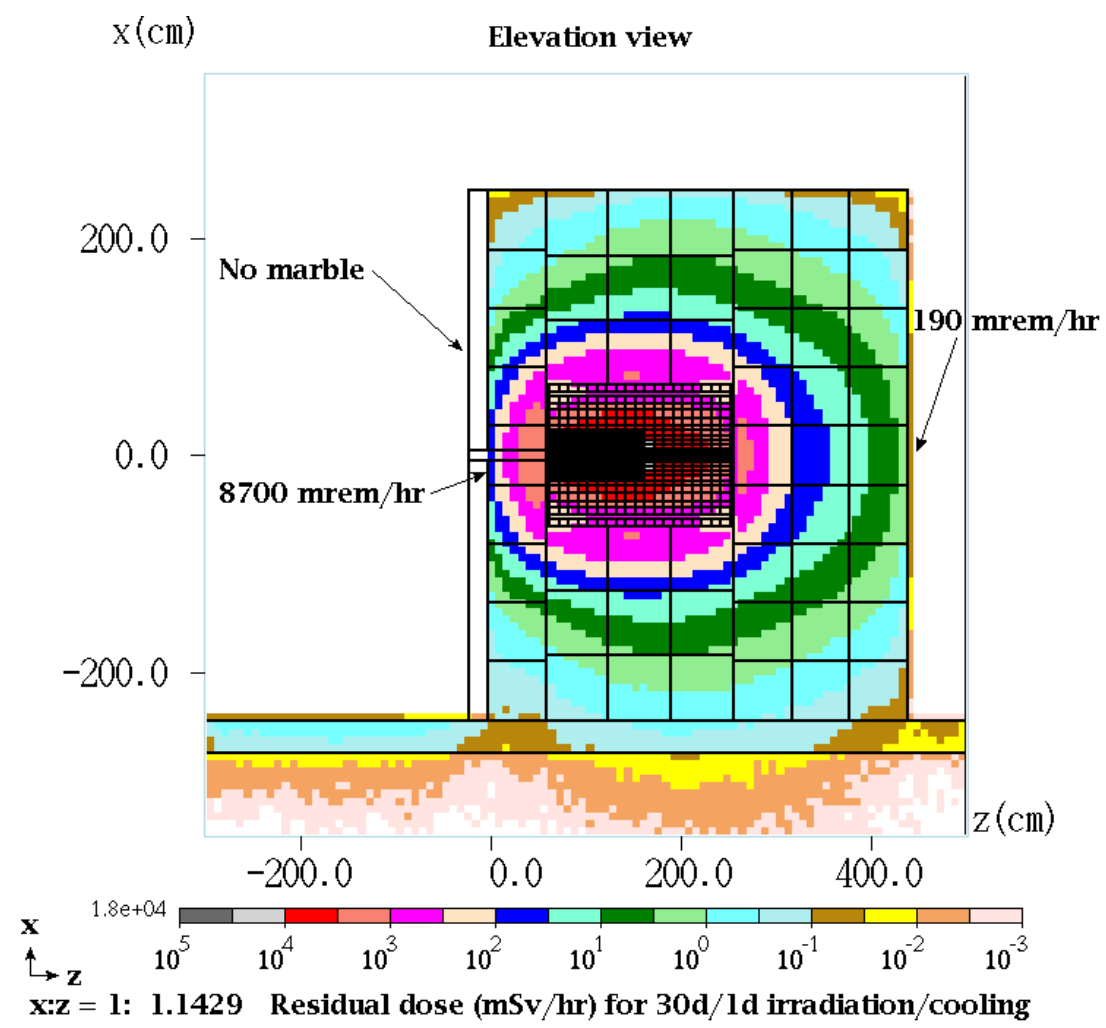

Fig. 7. A calculated residual dose distribution in the Beam Absorber without marble for a 30-day irradiation and 1-day cooling scenario.
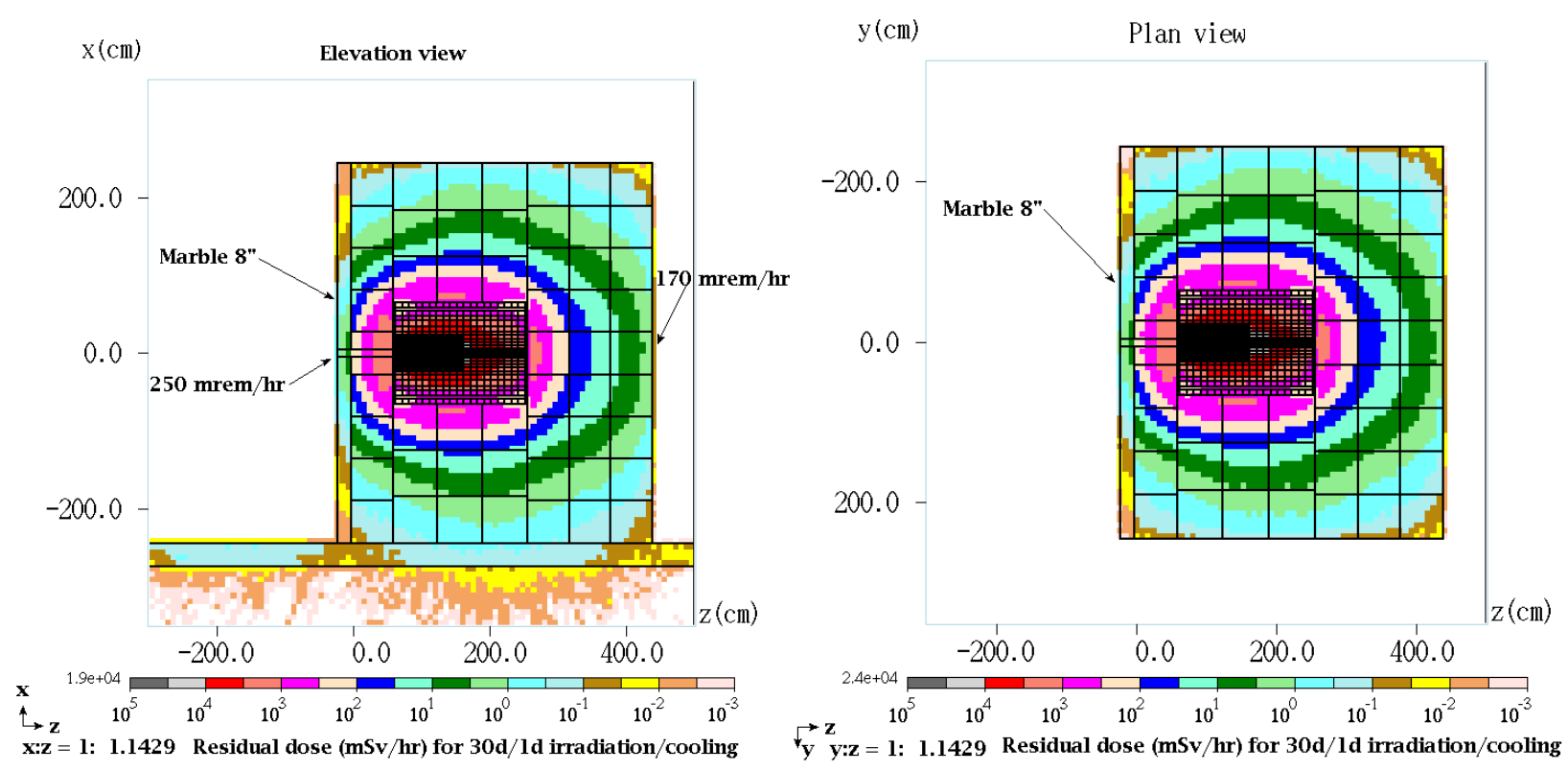

Fig. 8. A calculated residual dose distribution in the Beam Absorber with marble on the front face. A 30-day irradiation and 1-day cooling scenario was used. 
The calculated distribution of star density around the Beam Absorber is presented in Fig. 9. This quantity is directly related to ground and surface water activation. The peak value of $3.3 \times 10^{4}$ $\mathrm{star} /\left(\mathrm{cm}^{3 *} \mathrm{~s}\right)$ in soil is only slightly higher than that previously calculated for the Main Injector collimator region [6].

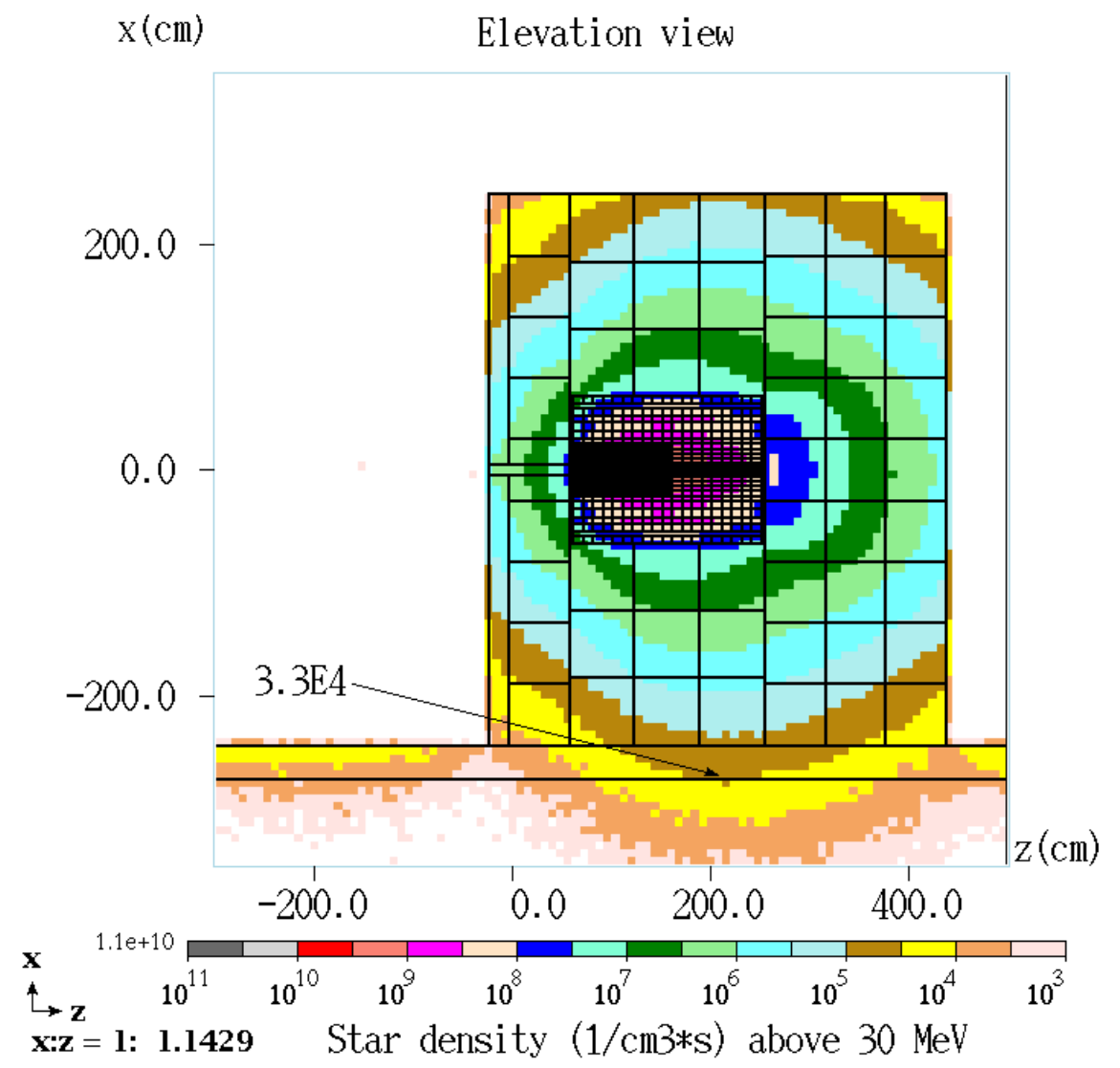

Fig. 9. A calculated distribution of star density above $30 \mathrm{MeV}$ around the Beam Absorber.

\subsection{A $5-\mathrm{kW}$ case}

The portable absorber for the reduced beam power case features smaller both absorber core and concrete shielding. The amount of cooling water lines was also significantly reduced. When compared to the 50-kW case (see Fig. 3), length of the second part of the absorber core was reduced by $60 \mathrm{~cm}$ (see Fig. 10). In transverse direction, the extra layers of aluminum and steel are removed. Thickness of the concrete shielding was reduced by several feet.

The calculated power density distribution is presented in Fig. 11. The calculated star density distribution around the absorber is shown in Fig. 12. One can see that the peak star density in the soil under the portable absorber is relatively high [6], so that some extra steel or concrete layers (or both) may be required in order to reduce surface water activation under the portable absorber. The calculated residual dose distributions (see Fig. 13) reveal that a marble layer on front face of the portable absorber as thick as 3 " or $4 "$ "will be necessary to reduce the residual dose to an acceptable level of $1 \mathrm{mSv} / \mathrm{hr}$. 


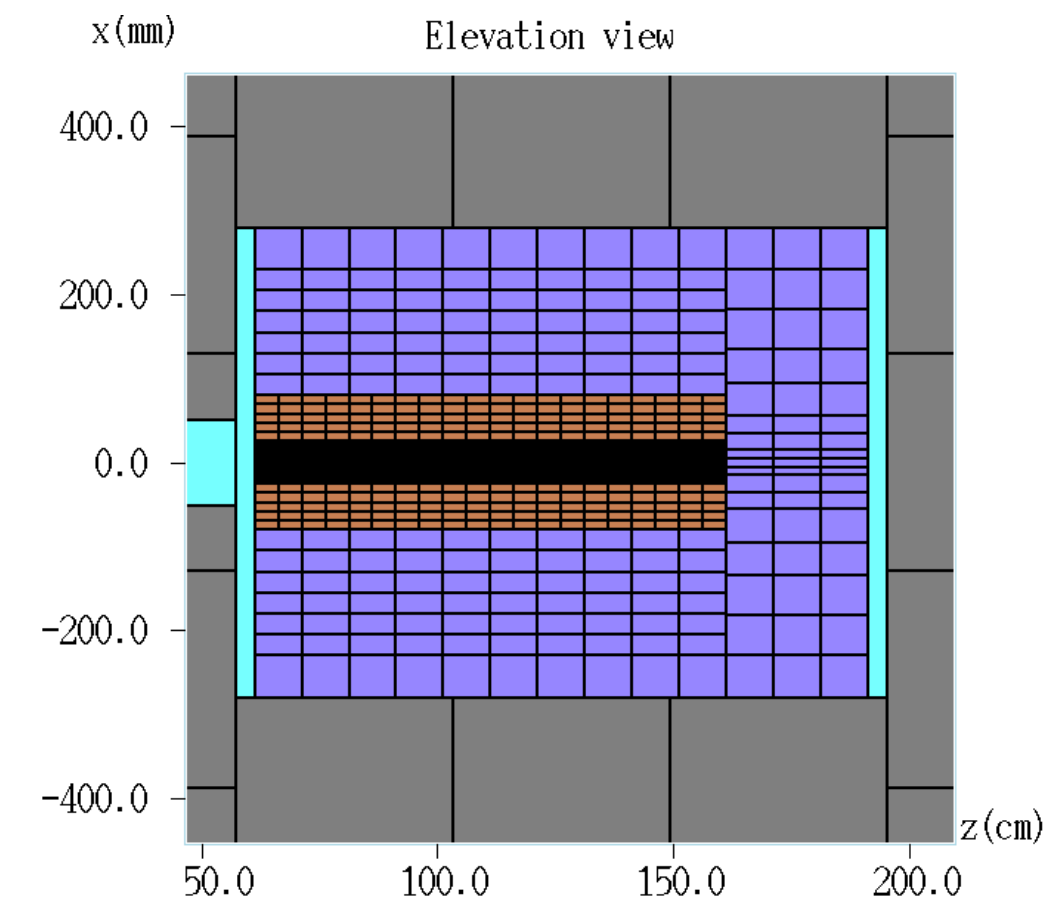

$\mathbf{x}$
$\stackrel{\leftrightarrow}{ } \mathbf{z}$
$\mathbf{x}: \mathbf{z}$

$\mathrm{x}: \mathrm{z}=1: 1.7773 ; \mathrm{y} 0=0.0000 \mathrm{~cm}$

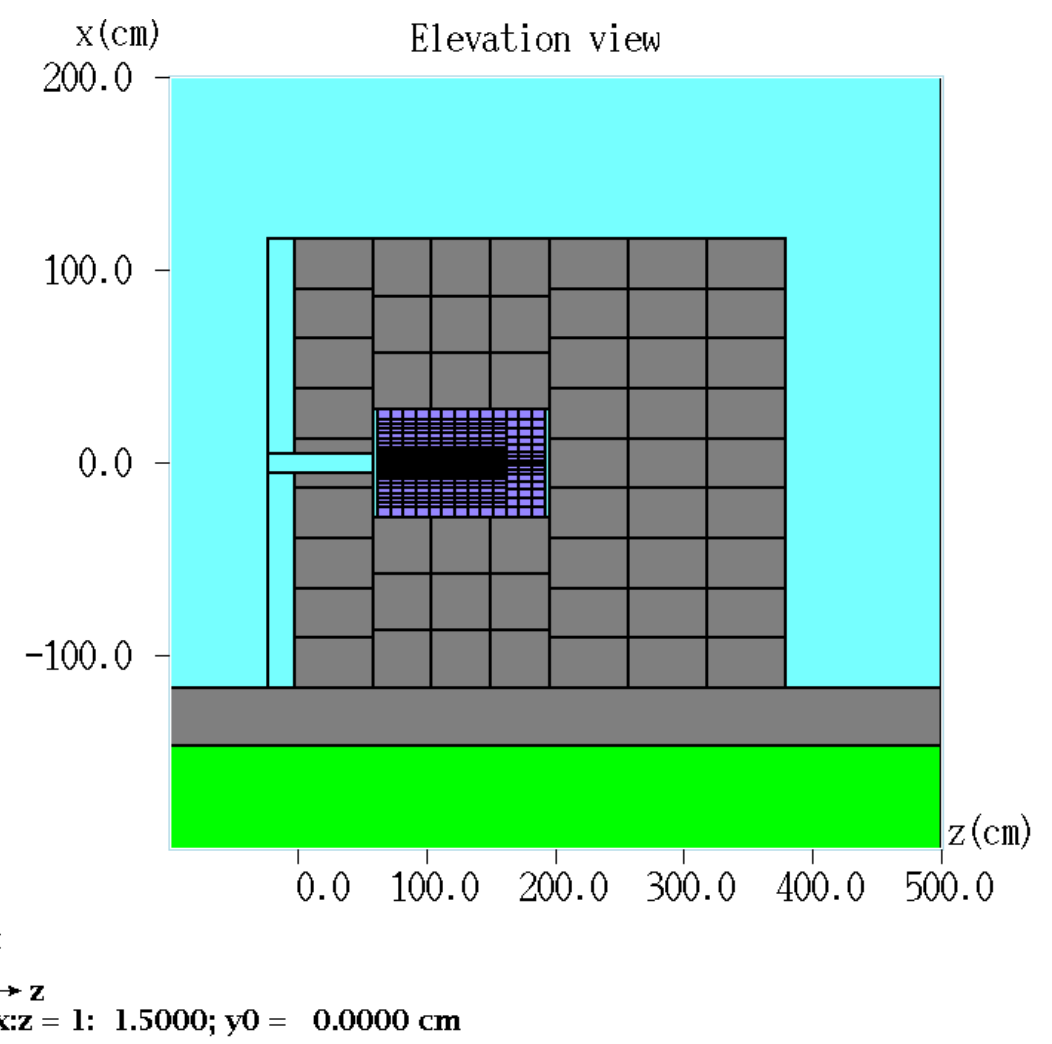

Fig. 10. A MARS15 model of the portable absorber core (top) and full model of the absorber (bottom). 


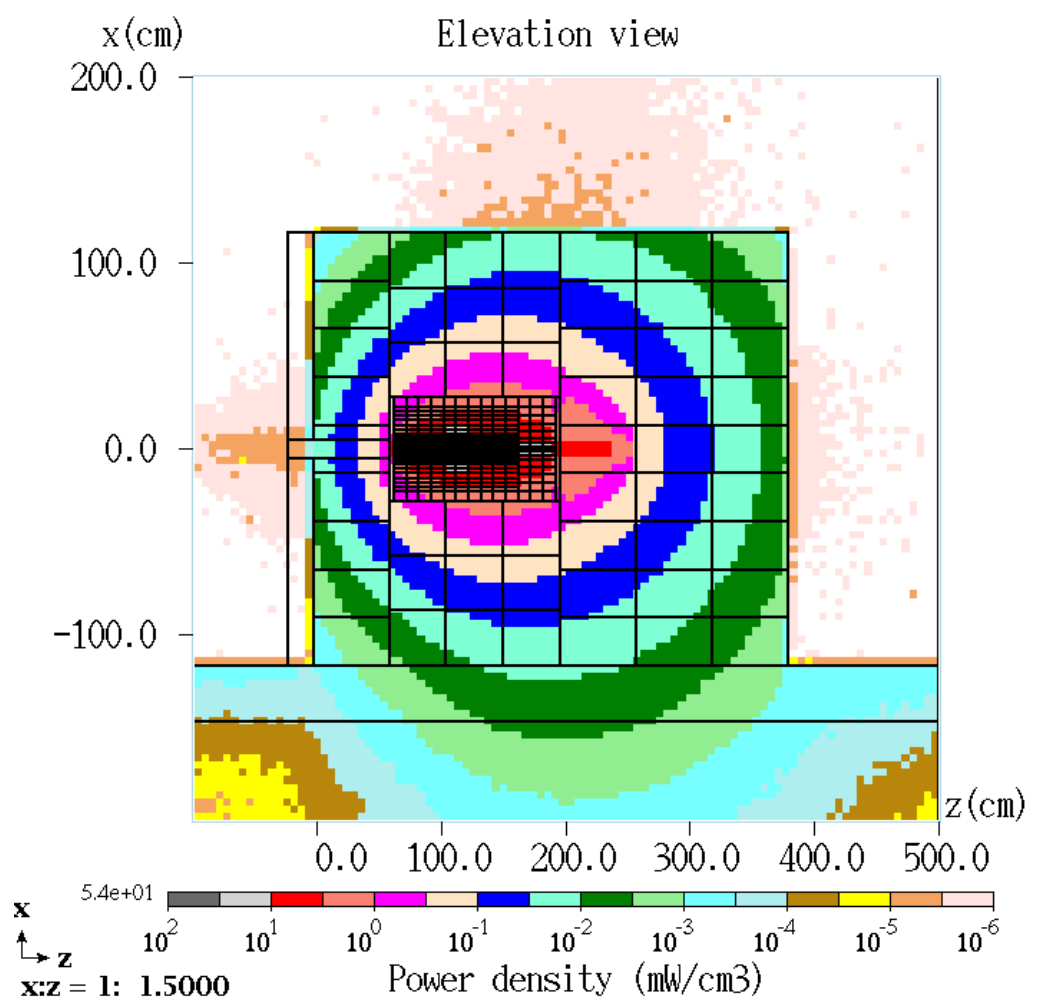

Fig. 11. A calculated power density distribution in the portable absorber core and surrounding concrete shielding.

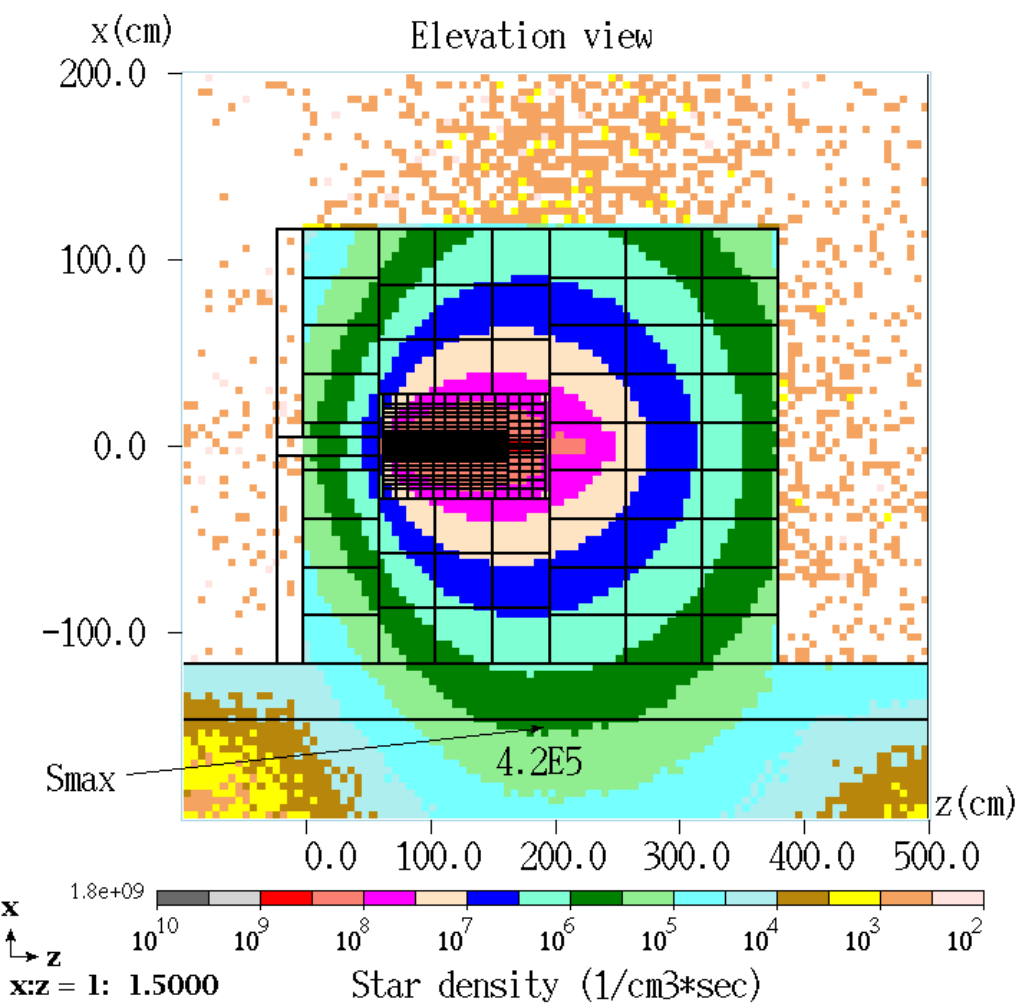

Fig. 12. A calculated distribution of star density above $30 \mathrm{MeV}$ around the portable absorber. 

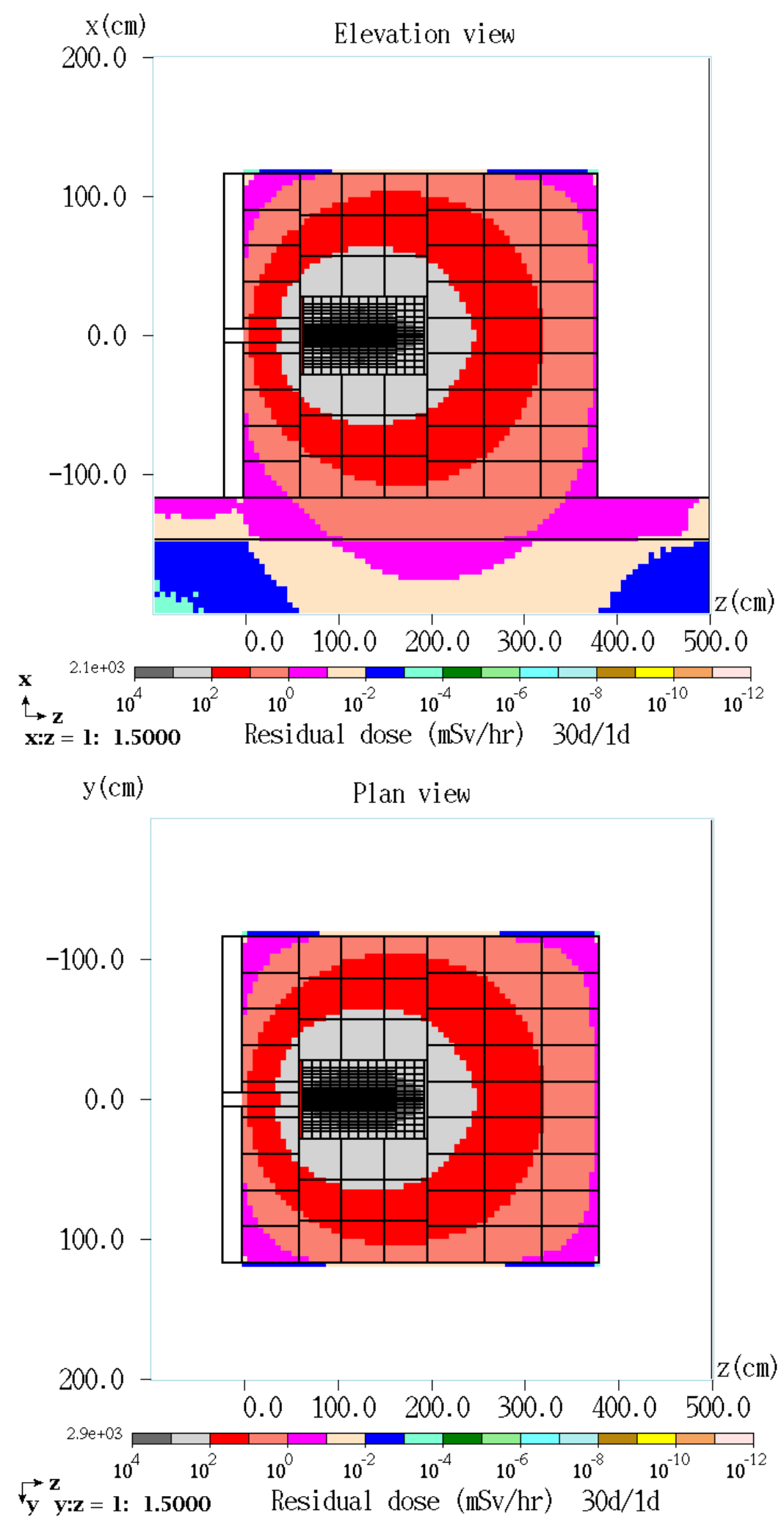

Fig. 13. A calculated residual dose distribution in the portable absorber without marble on the front face: elevation (top) and plan view (bottom). A 30-day irradiation and 1-day cooling scenario was used. 


\section{Thermal analysis for the $50-\mathrm{kW}$ case}

\subsection{Beam absorber design concept}

Graphite POCO TM grade is selected as the core material, for its properties of low atomic number, low mass density, high melting point, and high thermal shock resistance. It will be shrink-fitted to the aluminum outer jacket. On the aluminum outer jacket there are 24 gun-drilled water cooling channels, with half of them forming a redundant set. A $7.25 \mathrm{~cm}$ thick steel box with a rail system is placed inside the concrete chase, to allow for the beam dump replacement.

\subsection{Finite element model and cooling boundary conditions}

The FEA model is created with zoning corresponding to MARS RZ-distribution of energy deposition, shown in Fig. 14. With a $63 / 4$ inch channel and a 4 gpm water flow rate, a heat transfer coefficient of $4000 \mathrm{~W} / \mathrm{m}^{2}-\mathrm{K}$ could be reached on the interior of cooling channels. The cooling on the shielding is through stagnant air convection on the exterior surfaces, with a heat transfer coefficient of $5 \mathrm{~W} / \mathrm{m}^{2}-\mathrm{K}$ at $30^{\circ} \mathrm{C}$.

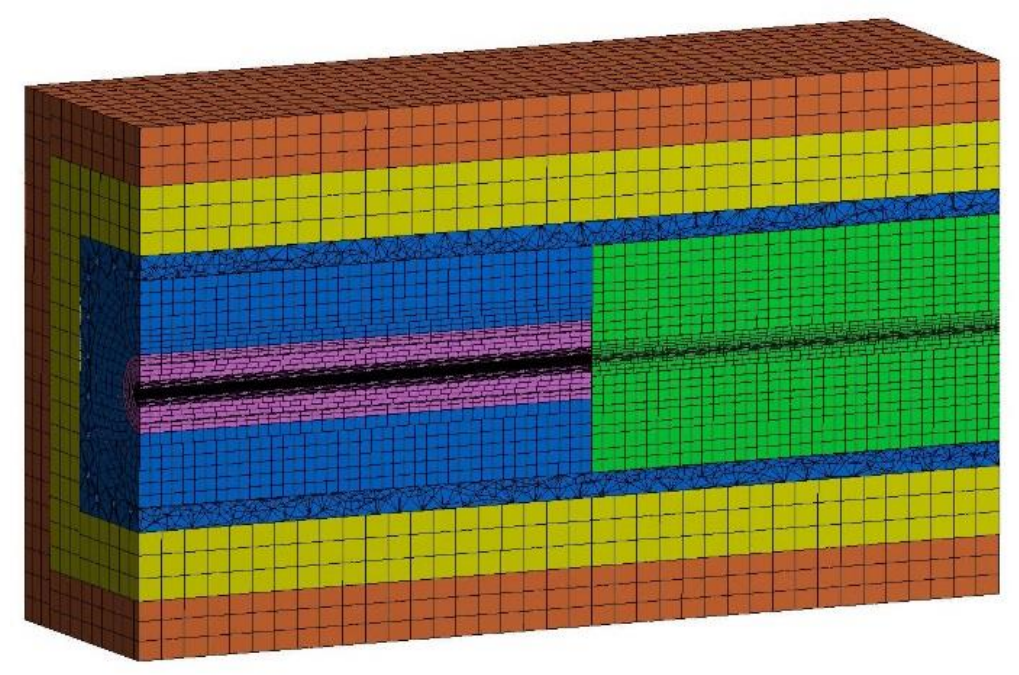

Fig. 14. FEA model cross-sectional view

\subsection{Beam absorber temperature at steady state}

For the steady state case, the energy deposition values are averaged over $0.05 \mathrm{~s}$ beam spill cycle time and are shown in Fig. 15. The peak heat load density is $34.52 \mathrm{~W} / \mathrm{cm}^{3}$. The total heat load is $49 \mathrm{~kW}$ on the beam dump and $2.4 \mathrm{~kW}$ on the concrete shielding. 


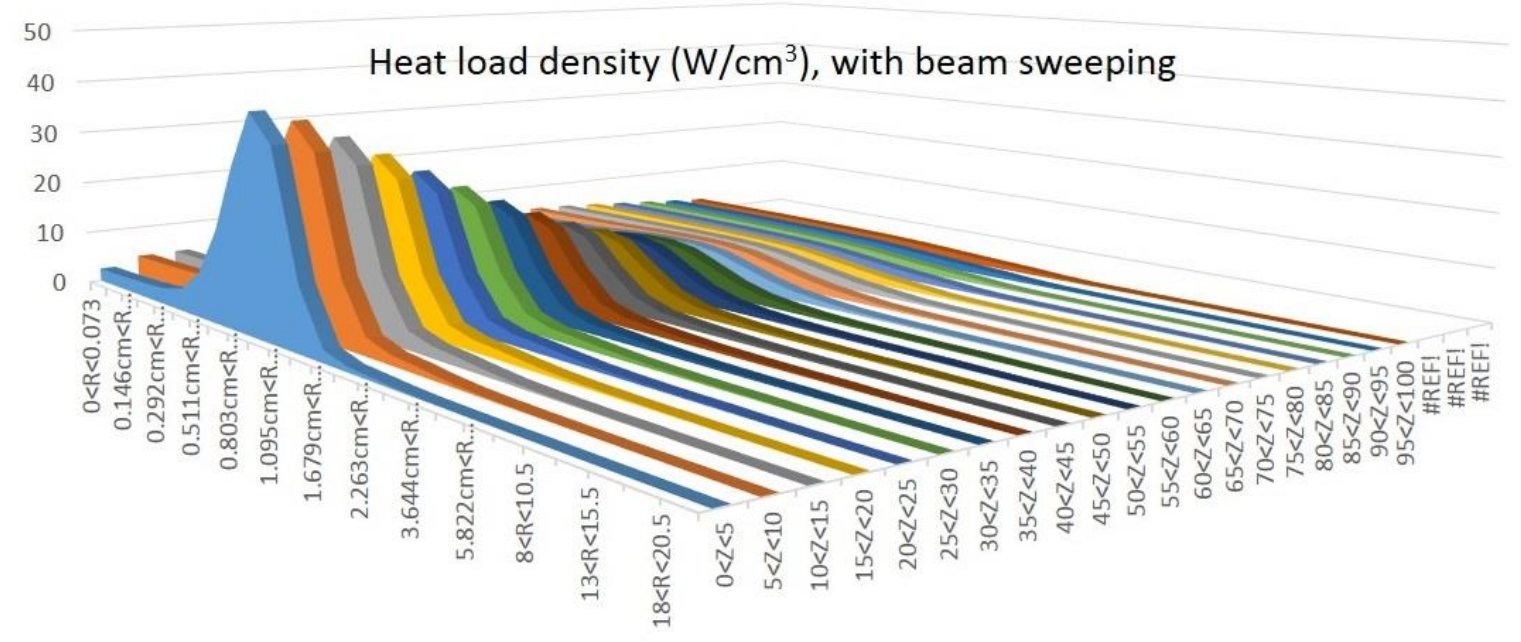

Fig. 15. Heat load profile in beam dump

The resulting peak temperature will be $213{ }^{\circ} \mathrm{C}$ on the graphite core, shown in Fig. 16 .

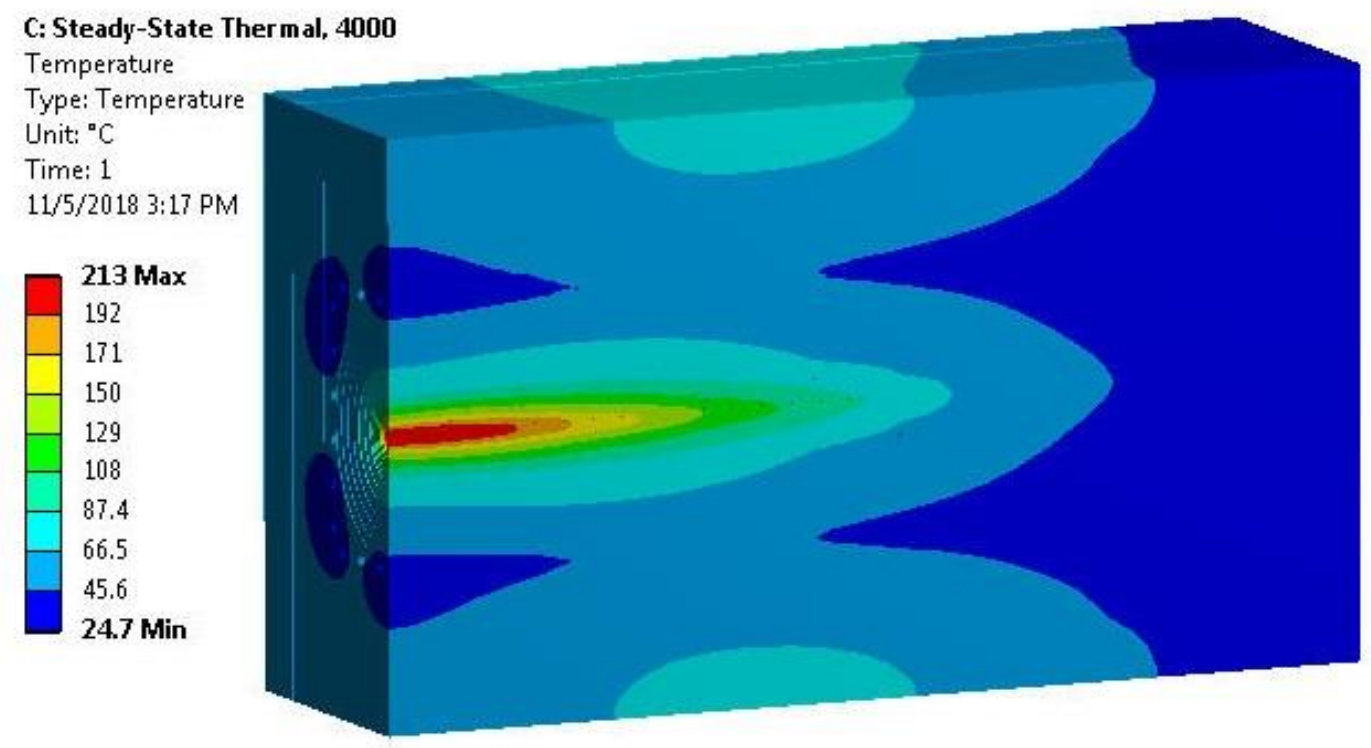

Fig. 16: Temperature in 50-kW beam dump at steady state (cross-sectional view)

5.4. Concrete shielding temperature at steady state

In the concrete shielding, the peak temperature will be $89^{\circ} \mathrm{C}$, shown in Fig. 17. 


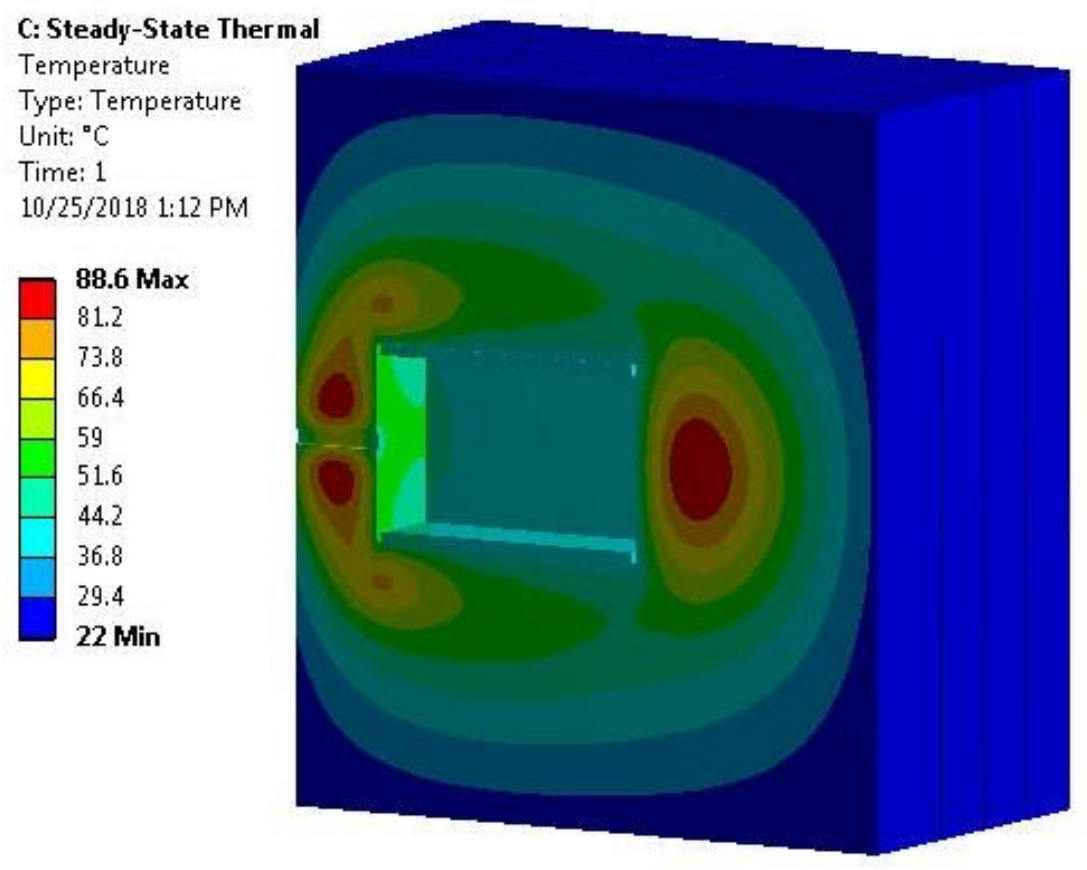

Fig. 17: Temperature in concrete shields at steady state (cross-sectional view)

\section{Thermal analysis for the $5-\mathrm{kW}$ case}

The 5-kW beam dump consists only of the graphite core, aluminum outer jacket and aluminum backstop, and it is $0.6 \mathrm{~m}$ shorter than the full size $50-\mathrm{kW}$ dump. Only two sets of cooling lines with a $1 \mathrm{gpm}$ water flow are needed. The peak temperature will be $70{ }^{\circ} \mathrm{C}$, shown in Fig. 18

C: Steady-State Thermal 1000

Temperature

Type: Temperature

Unit: ${ }^{\circ} \mathrm{C}$

Time: 1

12/12/2018 10:42 AM
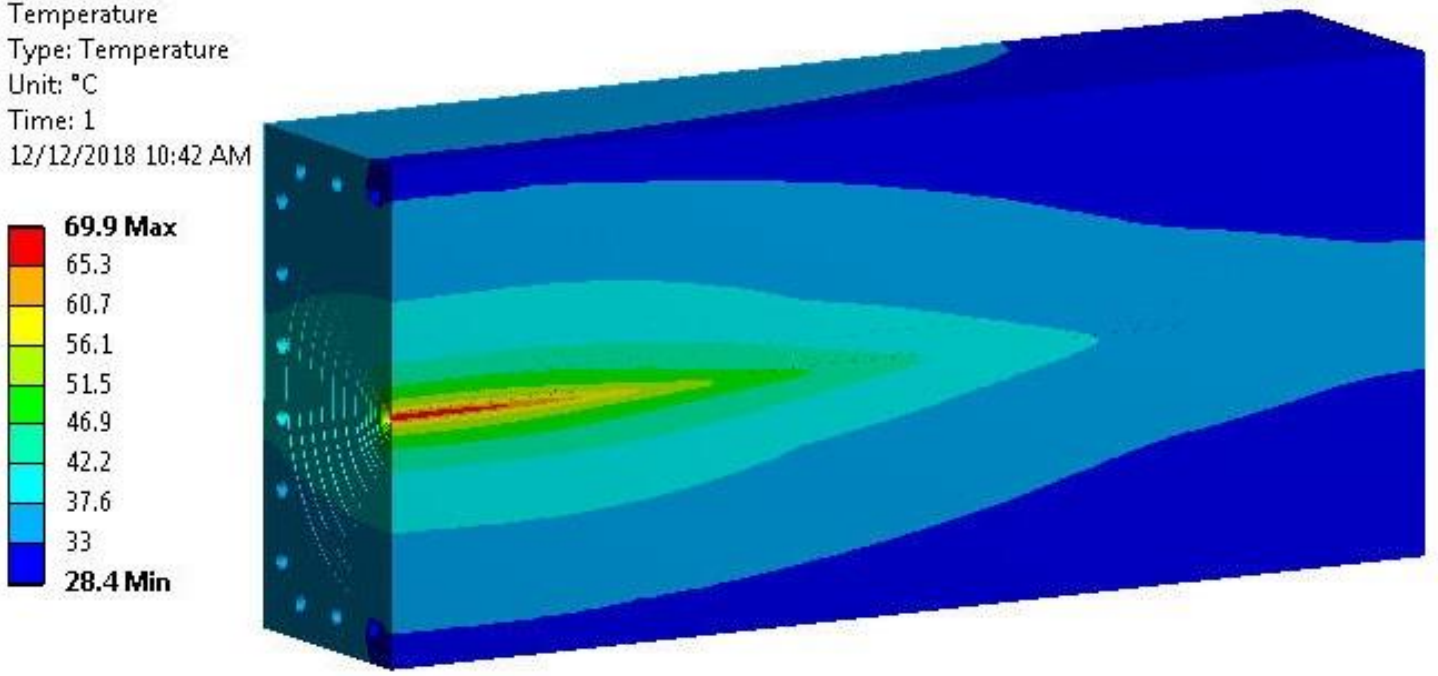

Fig. 18: Temperature of 5-kW beam dump at steady state (cross-sectional view) 


\section{References}

[1] PIP-II Conceptual Design Report, v0.03, April. 2018, docdb PIP-II-doc-113-v-10: http://pip2docdb.fnal.gov/cgi-bin/RetrieveFile?docid=113\&filename=PIP-II_CDR_v.0.3.pdf\&version $=10$

[2] N. V. Mokhov, "The MARS Code System User's Guide, Version 15 (2018)", Fermilab-FN-1058-APC (2018); https://mars.fnal.gov/

[3] N. V. Mokhov et al., "MARS15 code developments driven by the intensity frontier needs", Progress in Nuclear Science and Technology, v.4, 496 (2014).

[4] Yun He, “PIP-II Transfer-line Beam Dump Design”, ED0008532.

[5] Fermilab Radiological Control Manual, http://eshq.fnal.gov/manuals/frem/.

[6] I. Rakhno, "Radiation shielding for the Main Injector collimation system," Fermilab-Conf08-146-APC (2008). 